\title{
Hydrocephalus and Hirschsprung's disease in a patient with a mutation of L1CAM
}

\author{
Nobuhiko Okamoto, Yoshinao Wada, Megumi Goto
}

\begin{abstract}
Abnormalities of the L1CAM gene, a member of the immunoglobulin gene superfamily of neural cell adhesion molecules, are associated with $X$ linked hydrocephalus and some allelic disorders. We describe a patient with $X$ linked hydrocephalus and Hirschsprung's disease (HSCR) with a novel mutation in the L1CAM gene. This is the first report of HSCR with a mutant neural cell adhesion molecule. Although the disease phenotypes of this patient may well be independent, the alternative explanation that L1CAM mutations may contribute to both phenotypes cannot be excluded in view of an earlier report on another patient with both $\mathrm{X}$ linked hydrocephalus and HSCR. ( 7 Med Genet 1997;34:670-671)
\end{abstract}

Keywords: X linked hydrocephalus; L1CAM; HSAS syndrome; Hirschsprung's disease

X linked hydrocephalus (XLH), HSAS (hydrocephalus owing to congenital stenosis of the aqueduct of Sylvius, McKusick 307000) syndrome, is characterised by severe mental retardation, spastic tetraplegia, and bilateral adducted thumbs. Abnormalities in the LICAM gene, a member of the immunoglobulin gene superfamily of neural cell adhesion molecules, underlie this syndrome. ${ }^{1}$ Reports on new mutations in the LICAM gene are accumulating. ${ }^{2-7}$ HSCR is a neurocristopathy characterised by the absence of parasympathetic ganglion cells of the terminal hindgut. To date, mutations in the RET proto-oncogene, ${ }^{89}$ EDNRB (endothelin receptor B), ${ }^{10}$ and EDN3 (endothelin 3) ${ }^{11}{ }^{12}$ have been reported in HSCR cases. We present a patient with $\mathrm{XLH}$ resulting from a 2 bp deletion in exon 18 of the L1CAM gene, who had cleft palate and Hirschsprung's disease (HSCR).

\section{Case report}

The patient was the first child of nonconsanguineous, healthy Japanese parents. The family history was negative for neurological abnormalities and HSCR. Fetal ultrasonography showed congenital hydrocephalus at 25 weeks of gestation. After birth, cleft palate, micrognathia, abdominal distension, bilateral adducted thumbs, and flexion contractures of the fingers were noted. CT scan showed marked dilatation of the lateral ventricles. The diagnosis HSCR of rectosigmoid type was made. Corrective surgery for HSCR and ventriculoperitoneal shunting were success-

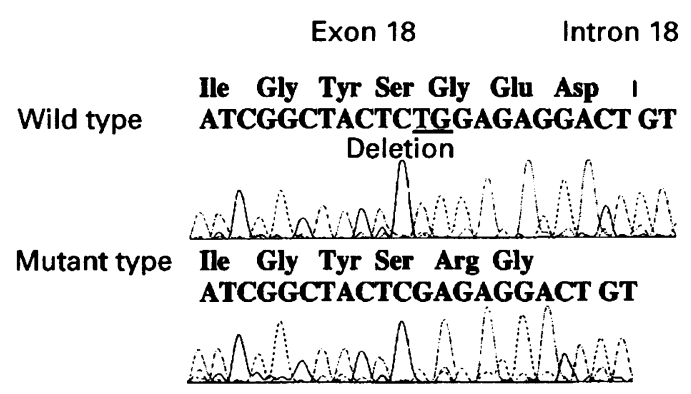

Figure 1 Sequence analysis of the L1CAM gene. Deletion of two bases in exon 18 was found.

fully performed. Histopathological studies of the resected segment of the colon showed aganglionosis consistent with HSCR. At the age of 3 years, he had severe mental retardation, spastic quadriplegia, and could not control his head. Ocular pursuit and response to sound were not evident. Neuroradiological studies showed enlarged lateral ventricles, agenesis of the corpus callosum and septum pellucidum, irregular ventricular wall, hypoplastic white matter, cerebellar hypoplasia, and fusion of the thalami. His typical neuroradiological findings prompted us to study the L1CAM gene.

\section{Materials and methods}

Blood samples were obtained from the patient with informed consent of his parents. DNA was extracted by the phenol/chloroform method. The primer sequences flanking the 28 exons of the L1CAM gene and PCR conditions have been reported by Jouet et al. ${ }^{2}$ In our study, PCR was performed in $100 \mu$ liquid comprising 85 $\mu l$ water, $10 \mu \mathrm{l} 10 \times \mathrm{PCR}$ buffer, $1 \mu \mathrm{l} 20 \mathrm{mmol} / 1$ dNTP mix, $50 \mathrm{pmol}$ of sense and antisense primers (preceded by $-21 \mathrm{M} 13$ universal and T7 primers, respectively), $1 \mu$ of genomic DNA, and $5 \mathrm{U}$ of Taq polymerase. The PCR conditions for amplifying exons 18 were $95^{\circ} \mathrm{C}$ for two minutes followed by 30 cycles of $95^{\circ} \mathrm{C}$ for one minute, $55^{\circ} \mathrm{C}$ for one minute, $72^{\circ} \mathrm{C}$ for one minute, and $72^{\circ} \mathrm{C}$ for four minutes. Direct sequencing of $P C R$ products was performed on both strands using the fluorescent dideoxy terminator method.

\section{Results}

Sequence analysis of exon 18 of the LICAM gene showed a 2 bp deletion (fig 1). The mother was heterozygous for the mutation. This deletion results in a frameshift and a premature stop codon. Translation of this mRNA will create a truncated protein without a transmembrane domain. 


\section{Discussion}

We found a novel mutation in the L1CAM gene in a patient with XLH associated with cleft palate and HSCR. Mutations in the LICAM gene have been found in XLH, ${ }^{1}$ MASA syndrome (mental retardation, aphasia, shuffling gait, and adducted thumbs), and $\mathrm{X}$ linked spastic paraplegia. ${ }^{2-4}$ The three disorders are allelic with overlapping profiles of clinical manifestations and intrafamilial heterogeneity. ${ }^{56}$ Fransen et al suggested that otopalatodigital syndrome, a bone disorder with cleft palate linked to $\mathrm{Xq} 28$, is an interesting disease in which to study the LICAM gene because LICAM is linked to Xq28 and activates fibroblast growth factor receptors. Although our patient had cleft palate, other manifestations were distinct from those of otopalatodigital syndrome.

This is the first report on the association of a defective L1CAM gene and HSCR. Although $\mathrm{XLH}$ and HSCR in our patient may well be independent, the alternative explanation that L1CAM mutations may contribute to both phenotypes cannot be excluded in view of an earlier report by Kaplan. ${ }^{13}$ She reported a 2 year old boy with psychomotor retardation, congenital unilateral ptosis, bilateral adducted thumbs, weakness of the upper limbs, and HSCR, with enlarged ventricles, complete agenesis of the corpus callosum, and hypoplasia of the inferior vermis and cerebellum. The maternal uncle of the proband also had marked psychomotor retardation and agenesis of the corpus callosum but no adducted thumbs or HSCR. A maternal third cousin had HSCR. The pedigree may have an L1CAM abnormality with intrafamilial heterogeneity.

The genotype-phenotype relationship in L1CAM abnormalities has not been fully established. None of the cases with mutations involving truncation of L1CAM before the transmembrane domain has been reported to have HSCR. However, in many cases the patients die in the newborn period and the appropriate postmortem examination for aganglionosis may not be complete. Clearly, if mutations in LICAM are involved in the development of HSCR, they may require interaction with other genetic or environmental factors for HSCR to be apparent. This would not be surprising in view of the fact that L1CAM is one component of a complex network of cell adhesion molecules, cytoskeletal elements, and signalling molecules that are involved in neuronal development. HSCR is attributed to a defect in migration of neural crest cells.

Since L1CAM is on the $\mathrm{X}$ chromosome, it might be speculated that it could contribute to the unexplained unequal distribution of HSCR in males and females (approximately 3:1 in Japan). Further clinical and molecular studies of similar patients are required to clarify the role of L1CAM in the development of intestinal ganglion cells.

1 Rosenthal A, Jouet M, Kenwrick S. Aberrant splicing of neural cell adhesion molecule Ll mRNA in a family with X-linked hydrocephalus. Nat Genet 1992;2:107-12.

2 Jouet M, Rosenthal A, Armstrong G, et al. X-linked spastic paraplegia (SPG1), MASA syndrome and X-linked hydrocephalus result from mutations in the L1 gene. Nat Genet 1994;7:402-7.

3 Vits L, Van Camp G, Coucke P, et al. MASA syndrome is due to mutations in the neural cell adhesion gene LICAM. due to mutations in the neura

4 Ruiz JC, Cuppens H, Legius E, et al. Mutations in L1-CAM in two families with $\mathrm{X}$ linked complicated spastic paraplegia, MASA syndrome, and HSAS. $\mathcal{F}$ Med Genet 1995;32: 549-52.

5 Kenwrick S, Jouet M, Donnai D. X linked hydrocephalus and MASA syndrome. $\mathcal{F}$ Med Genet 1996;33:59-65.

6 Fransen E, Vits L, Van Camp G, Willems PJ. The clinical spectrum of mutations in $\mathrm{L} 1$, a neuronal cell adhesion molecule. Am f Med Genet 1996;64:73-7.

7 Fransen E, Lemmon V, Van Camp G, et al. CRASH syndrome: clinical spectrum of corpus callosum hypoplasia, retardation, adducted thumbs, spastic paraparoplasia, retardation, adducted thumbs, spastic paraparesis and hydrocephalus due to mutation

8 Edery P, Lyonnet S, Mulligan LM, et al. Mutations in the RET proto-oncogene in Hirschsprung's disease. Nature 1994;367:378-80.

9 Romeo G, Ronchetto P, Luo Y, et al. Point mutations affectRomeo G, Ronchetto P, Luo Y, et al. Point mutations affect-
ing the tyrosine kinase domain of the RET proto-oncogene in Hirschsprung's disease. Nature 1994;367:377-80.

10 Puffenberger EG, Hosoda K, Washington SS, et al. A missense mutation of the endothelin-B receptor gene in multigenic Hirschsprung's disease. Cell 1994;79:1257-66.

11 Edery P, Attie T, Amiel J, et al. Mutation of the endothelin-3 gene in the Waardenburg-Hirschsprung disease (ShahWaardenburg syndrome) Nat Genet 1996;12:442-4.

12 Hofstra RMW, Osinga J, Tan-Sindhunata G, et al. A homozygous mutation in the endothelin -3 gene associated with a combined Waardenburg type 2 and Hirschsprung phenotype (Shah-Waardenburg syndrome). Nat Genet 1996;12:445-7.

13 Kaplan P. X linked recessive inheritance of agenesis of the corpus callosum. F Med Genet 1983;20:122-4. 